\title{
BMJ Open Adults' experiences of living with pulmonary hypertension: a thematic synthesis of qualitative studies
}

\author{
Gregg Harry Rawlings (D) , ${ }^{1}$ Nigel Beail (D) , ${ }^{1}$ lain Armstrong (D) , \\ Robin Condliffe (D), ${ }^{2}$ David G Kiely (D) ,,3 Ian Sabroe (D) ,4 \\ Andrew R Thompson (i) ${ }^{5}$
}

To cite: Rawlings GH, Beail N, Armstrong I, et al. Adults' experiences of living with pulmonary hypertension: a thematic synthesis of qualitative studies. BMJ Open 2020;10:e041428. doi:10.1136/ bmjopen-2020-041428

- Additional material is published online only. To view, please visit the journal online (http://dx.doi.org/10.1136/ bmjopen-2020-041428)

Received 10 June 2020 Revised 27 October 2020 Accepted 15 November 2020

Check for updates

(C) Author(s) (or their employer(s)) 2020. Re-use permitted under CC BY-NC. No commercial re-use. See rights and permissions. Published by BMJ.

${ }^{1}$ Clinical Psychology Unit, The University of Sheffield, Sheffield, UK

${ }^{2}$ Sheffield Pulmonary Vascular Disease Unit, Sheffield Teaching Hospitals NHS Foundation Trust, Sheffield, UK

${ }^{3}$ Department of Infection, Immunity and Cardiovascular

Disease, The University of

Sheffield, Sheffield, UK

${ }^{4}$ School of Medicine and

Biomedical Sciences, University of Sheffield, Sheffield, UK

${ }^{5}$ South Wales Clinical

Psychology Training Programme, Cardiff University, Cardiff, UK

Correspondence to

Dr Gregg Harry Rawlings;

ghrawlings1@sheffield.ac.uk

\section{ABSTRACT}

Objectives Pulmonary hypertension is a life-shortening disease that has a considerable impact on quality of life. Improving our understanding of how individuals are affected and cope with the disease will help to improve services and outcomes. This review synthesises the published qualitative research that has listened to adults discuss their experiences of living with the disease. Design A comprehensive systematic search of four databases was conducted in May 2020: Web of Science, PubMed, PsycINFO and Cochrane Library. Suitable studies were evaluated using the Critical Appraisal Skills programme. Findings from the studies were extracted and subjected to a thematic synthesis.

Results Nineteen articles were identified reflecting the experiences of over 1900 individuals impacted by pulmonary hypertension from Europe, North and South America and Asia. Ten studies did not report participant's WHO functional class of pulmonary hypertension, which resulted in comparing experiences between different severity difficult. All studies met the majority of the quality assessment items. Six descriptive themes emerged discussing participant's experiences of diagnosis, treatment, prognosis, healthcare professionals, impact and coping with pulmonary hypertension. Four higher order analytical themes were developed from the descriptive themes, reflecting: (i) uncertainties and anxiety that participants encountered related to pulmonary hypertension; (ii) lack of recognition of the impact of the condition; (iii) frustration at the paucity of awareness of pulmonary hypertension in society and healthcare settings and (iv) participant's accounts of transitioning through different stages of living with the disease.

Conclusions These findings form the first synthesis of experiences of life in individuals impacted by pulmonary hypertension and illustrate the multifaceted impact of the condition. The voices of numerous groups are missing from the literature highlighting the need for additional research. The results have implications for clinical practice emphasising the role of educational and psychological therapies to support those with the disease.

\section{INTRODUCTION}

Pulmonary hypertension (PH) describes a group of conditions characterised by elevated pulmonary artery pressure, which untreated
Strengths and limitations of this study

- This is the first systematic review of the impact of pulmonary hypertension on adults' experiences of living.

- A thematic synthesis approach was used, a key aim of which is to help inform future interventions, policy and clinical practice.

- A comprehensive search strategy was undertaken screening 9362 articles from four electronic databases.

results in right heart failure and premature death. Five groups each sharing clinical and pathophysiological features can be described: group 1: pulmonary arterial hypertension (PAH); group 2: PH due to left heart disease; group 3: PH due to lung disease or hypoxia; group 4: chronic thromboembolic $\mathrm{PH}$ and group 5: PH due to unclear or miscellaneous disorders. ${ }^{12}$ The WHO functional classification system in $\mathrm{PH}$ is an important tool used to reflect disease severity, and monitor progression of the disease and response to treatment. This index ranges from I, suggestive of patients experiencing no or minimal symptoms during physical activity, to IV indicative of patients experiencing severe symptoms at rest. $^{2}$

Despite improved outcomes in PH-related mortality associated with advancements in medical therapies, ${ }^{3-5}$ it remains, a lifeshortening condition with significant physical and psychological morbidity and a profound impact on quality of life (QoL) ${ }^{4}$ Recent research has explored patient's experiences of living with the disease, ${ }^{67}$ demonstrating the importance of psychosocial factors in $\mathrm{PH}$ on $\mathrm{QoL}^{8-10}$ and engagement in care. ${ }^{11}$ A greater understanding of how individuals are affected and cope with PH should help to improve treatment pathways and patientreported outcomes. ${ }^{7}$ 


\begin{tabular}{|c|c|c|}
\hline Concept 1 & AND & Concept 2 \\
\hline $\begin{array}{l}\text { Pulmonary } \\
\text { hypertension } \\
\text { OR Pulmonary } \\
\text { arterial } \\
\text { hypertension }\end{array}$ & & $\begin{array}{l}\text { Qualitative OR thematic } \\
\text { OR mixed*methods OR } \\
\text { experience* OR perspective* OR } \\
\text { semi*structured OR interview OR } \\
\text { phenomenolog* }\end{array}$ \\
\hline
\end{tabular}

This review systemically synthesises the published qualitative evidence examining adults' experiences of $\mathrm{PH}$. The majority of researchers in this area have employed quantitative methodologies. ${ }^{7}$ These studies have investigated a specific difficulty asking individuals to answer a series of structured questions by endorsing predefined responses. ${ }^{12-14}$ While this has produced large generalisable datasets, participants may not have been able to discuss experiences most important to them. Qualitative methods, however, allow participants to describe their experiences, in their own words, meaning rich and finegrained data can be collected. The objective of this review was to provide a more in-depth and nuanced understanding of experiences, highlight unmet needs and identify new areas of investigation. ${ }^{15}$ For instance, the current findings were used to help guide the development of a self-help intervention for anxiety in $\mathrm{PH}$.

\section{METHODS}

\section{Search strategy}

This systematic review has been conducted in accordance with Preferred Reporting Items for Systematic Reviews and Meta-Analyses and Enhancing Transparency in Reporting the Synthesis of Qualitative Research (ENTREQ) ${ }^{16}$ (online supplemental 1 and 2). A comprehensive search of four databases was performed in January 2020, which was repeated in May 2020 prior to submission: Web of Science, PubMed, PsycINFO and Cochrane Library. The references of suitable articles were searched for relevant studies: this helped to identify one additional article ${ }^{17}$ (tables 1 and 2). Search terms were informed by author's experience of previously published articles on PH. We used the term 'pulmonary hypertension' to remain inclusive as this is likely to also identify other groups of $\mathrm{PH}$. Keywords of several suitable articles were checked to confirm salient words had not been omitted.

\section{Quality assessment}

Relevant studies were evaluated using the 10-item Critical Appraisal Skills Programme for qualitative research. ${ }^{18} \mathrm{An}$ overall score was given to each article demonstrating that the study had achieved the majority or all $(++)$, most $(+)$ or few (-) of the criteria. The lead author (GHR) assessed all articles. A second researcher (CG) independently re-assessed approximately one-quarter of the papers $(n=5)$ chosen as random. Following discussion, a $92 \%$ level of agreement per study was observed for all 11 items (including the overall score) per study, compared with an $87 \%$ level of agreement prior to discussion. All findings, regardless of quality, were included in the synthesis to remain inclusive.

\section{Data analysis}

A thematic synthesis was adopted using four stages ${ }^{19}$ :

1. GHR read each paper before extracting relevant information.

Table 2 Inclusion and exclusion criteria-based on the spider tool ${ }^{61}$

\begin{tabular}{lll} 
& Inclusion & Exclusion \\
\hline Sample & Adults (18 years or older) diagnosed with $\mathrm{PH}$; participants & Children (aged $<18$ years), individuals without a \\
& who self-reported being impacted by a diagnosis of $\mathrm{PH}$. & diagnosis of $\mathrm{PH}$. \\
& We assumed participants were adults unless otherwise & \\
& stated. &
\end{tabular}

Phenomenon of Exploring individual's experiences of $\mathrm{PH}$, that is, interest diagnosis, treatment, psychosocial impact.

Design study that reported utilising a qualitative research
methodology that is, open-ended question (sometimes
known as Big ' $Q$ ') was considered. If participants with $P H$
were grouped with individuals with a different diagnosis,
their unique contribution must be made explicit.

Evaluation

Any form of qualitative analysis that aim to report on subjective experiences, that is, thematic analysis, interpretative phenomenological analysis.

Research type Published in English in a scientific journal and peer reviewed. No date restrictions were applied. 


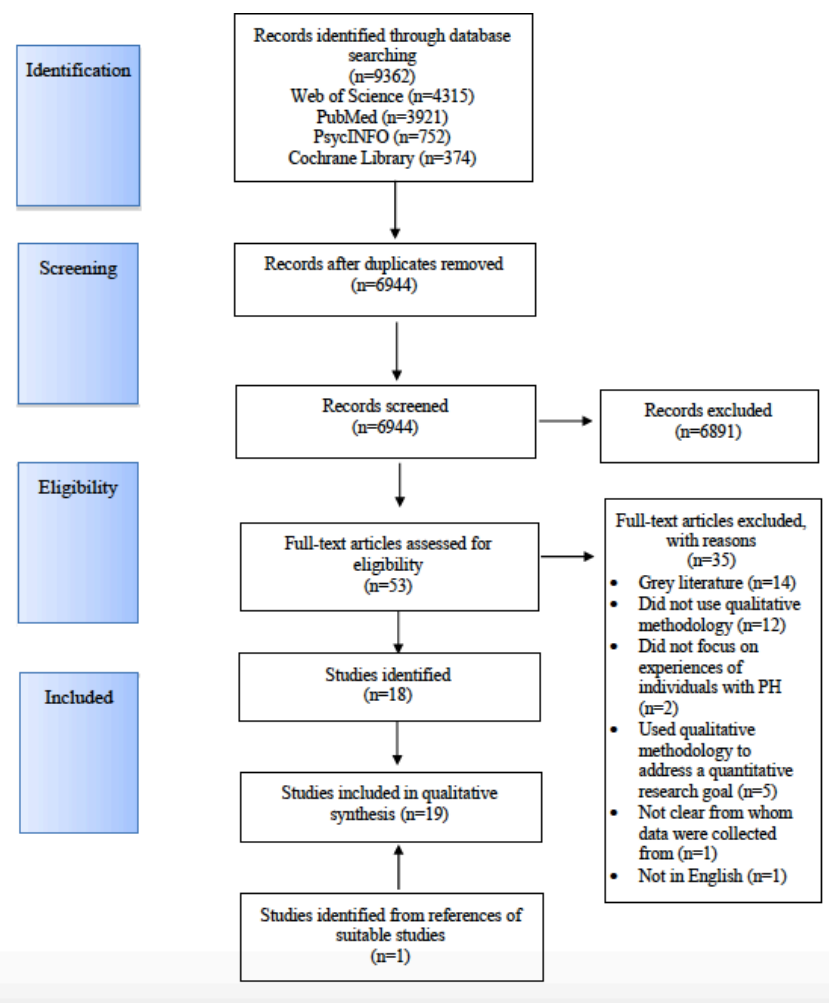

Figure 1 Preferred Reporting Items for Systematic Reviews and Meta-Analyses diagram. PH, pulmonary hypertension.

2. Findings were iteratively coded by GHR with the aim of developing descriptive themes. Themes were informed by frequency and saliency of codes, as opposed to study characteristics (ie, sample size).

3. Analytical themes were developed, which aimed to go beyond the original data and descriptive themes in context of the review's objective. Themes were discussed among other members of the research team.

4. Final report was written, and suitable quotations were selected. " have been used when reporting participants' words and " 'for authors.

\section{Patient public involvement}

There was no patient and public involvement in this systematic review.

\section{RESULTS}

\section{Findings of search}

Overall, 19 studies were included in the synthesis (figure 1). Studies were published between 2005 and 2020; however, $18 / 19$ were published in the last 10 years. ${ }^{20}$ Data reflect over 1900 individuals across Europe, North and South America and Asia. Ages ranged from 19 to 91 years. In all but one study, the samples were predominantly female $^{21}$-likely reflecting the gender bias observed in $\mathrm{PH}^{22}$ Only three studies provided sufficient detail regarding sample ethnicity. ${ }^{17} 2324$ Participants had been diagnosed with $\mathrm{PH}$ ranging from $<1$ year to 24 years. Ten studies failed to report medical information concerning participant's functional class-this is important given that experiences seemed to differ depending on diseasespecific issues. ${ }^{1725}$ The majority $(n=14)$ of studies used research interviews for data collection, whereas greater variation of analytical methods was used (table 3 ).

\section{Quality assessment}

All studies met the majority of the 10 quality assessment items (table 4). Seven studies failed to justify their decision for using a qualitative approach and one study provided a limited description of their data analysis method. Surprisingly, 15 articles did not report their method of reflexivity.

\section{Descriptive themes}

Six descriptive themes emerged:

\section{Diagnosis}

Participants reported experiencing PH-related symptoms a "long" time $\left[{ }^{27}\right.$, p. E19] prior to obtaining a diagnosis. ${ }^{21} 2627$ This period was characterised by a decline in physical functioning, QoL and emotional and social difficulties. ${ }^{202} 2829$ During this time, and thereafter, individuals expressed confusion over the cause of their experiences ${ }^{28}$ - worries that were not necessarily reduced by the diagnosis, which was described as having posed "more questions than it answers" [22, p. 3]. Participants tended to avoid, adapt to or explain away their symptoms: "[I] just assumed that everything was down to smoking" [27, 28, p. 4].

Participants described undergoing a series of examinations, referrals and misdiagnoses to find an explanation for their experiences. ${ }^{26-29}$ This process left participants feeling 'frustrated' [21, p. 103], 'uncertain' [26, p. 611], angry and "disillusioned" with the perceived meaning of their symptoms [28, p. 6]. Receiving the diagnosis was described as 'life-changing' [37, p. 4]. While people responded differently, for instance, expressing feelings of 'relief - as they can now receive treatment [22, p. 3]-'shock' [30, p. 38], helplessness ${ }^{30}$ and confusion, ${ }^{26}$ a strong emotional response was evident. ${ }^{31}$ Following the diagnosis, individuals ruminated over the cause of their disease. $^{27}$

\section{Treatment}

Participants discussed their reliance on specialist centres, ${ }^{621}$ which helped reduce feelings of uncertainty by answering questions and dispelling false narratives about PH: 'it (the diagnosis) wasn't as devastatingly unhopeful as first appeared' [28, p. 7]. A disparity in care between services was described, ${ }^{6}$ specifically, between specialist centres and community services in terms of knowledge, treatments and approach to care. ${ }^{21} 2831$ Many participants expressed the need for greater collaboration between services. ${ }^{6212627}$

Individuals often discussed how they felt their care could be improved, which included, regular checkups, ${ }^{24}$ receiving more information, ${ }^{27} 32$ promoting shared decision making ${ }^{26}$ and holistic care ${ }^{33}$ and involving family members. ${ }^{27}$

Participants did not view medication as a "cure" [29, p. 2], but rather to alleviate symptoms, improve health and 


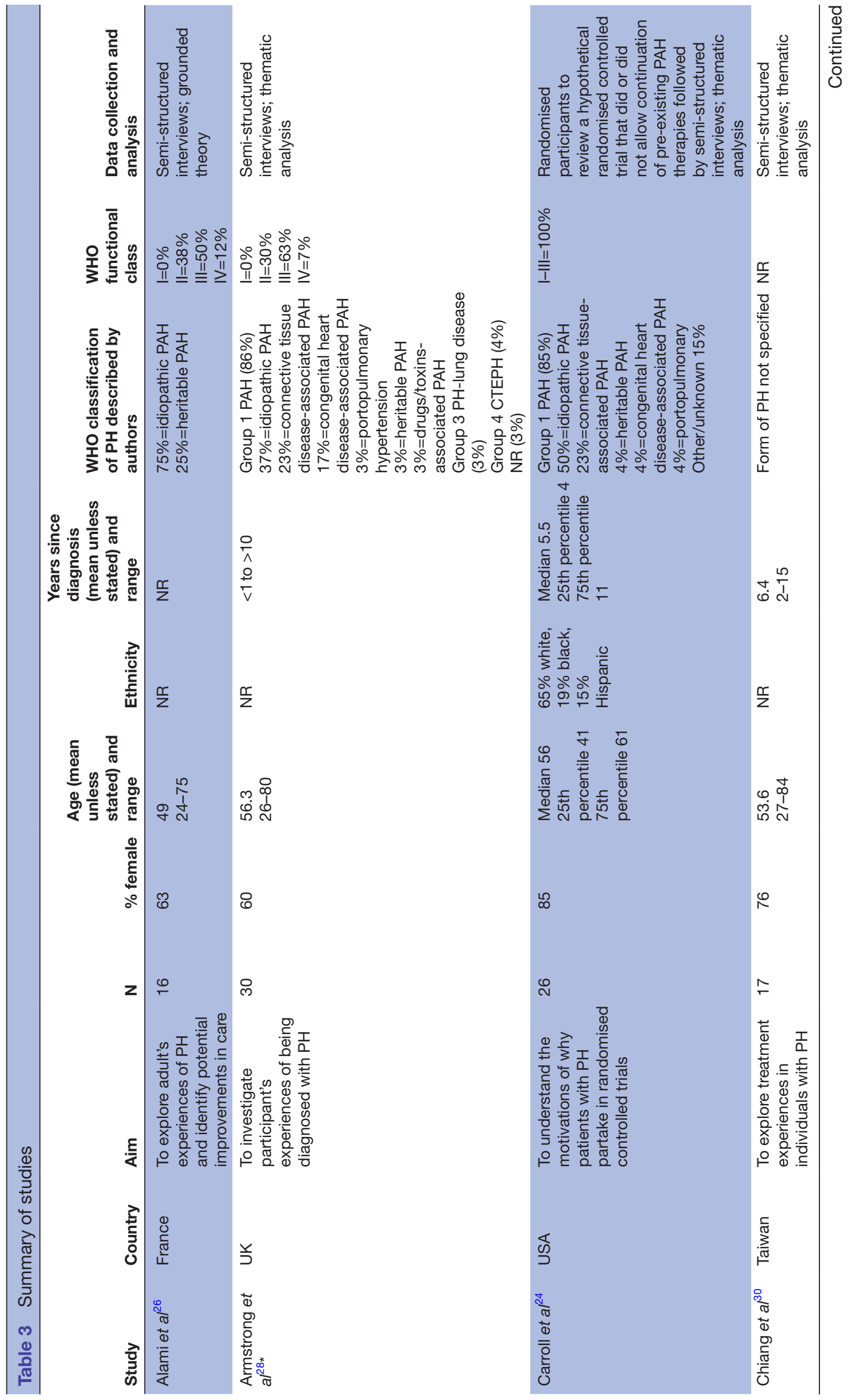




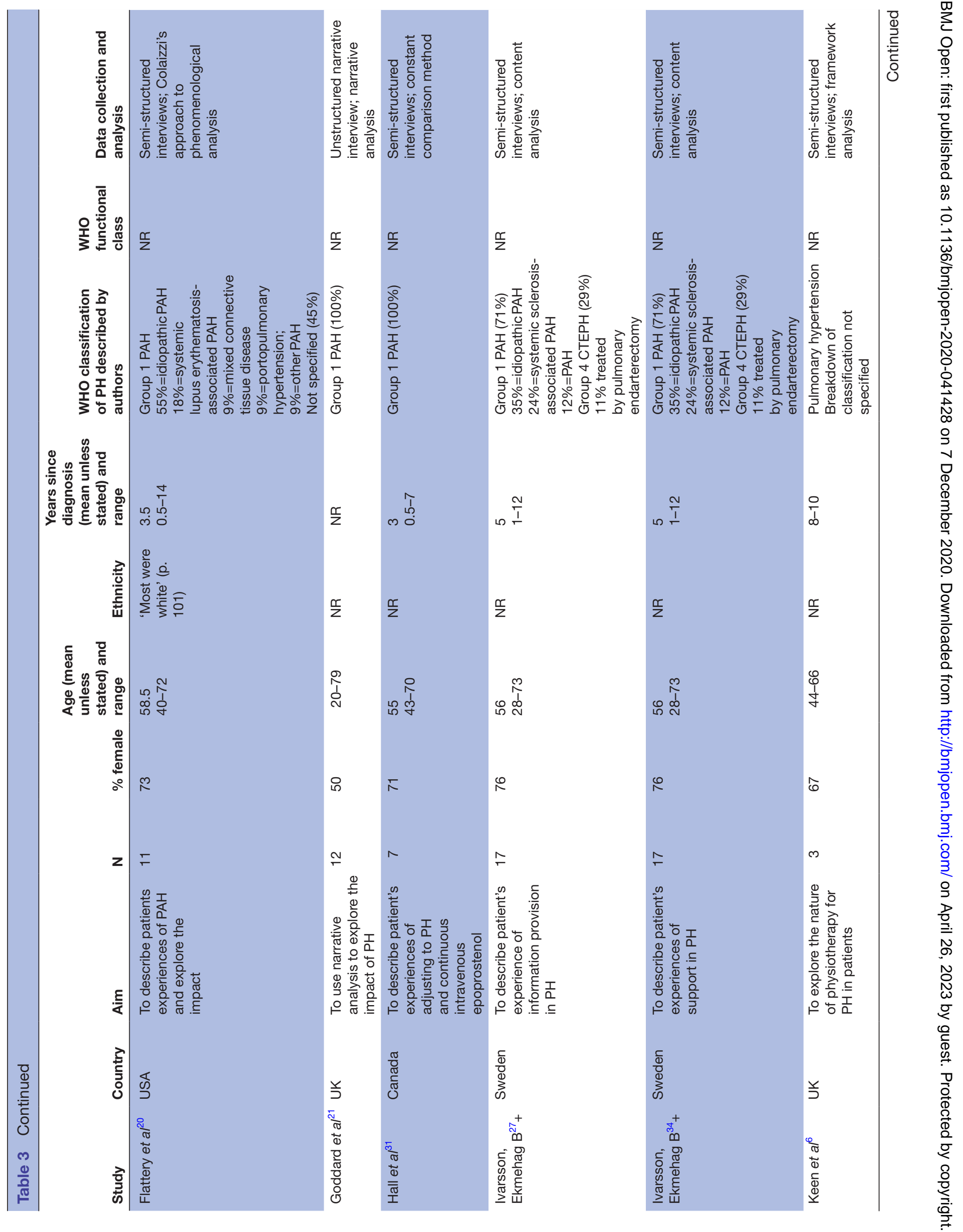




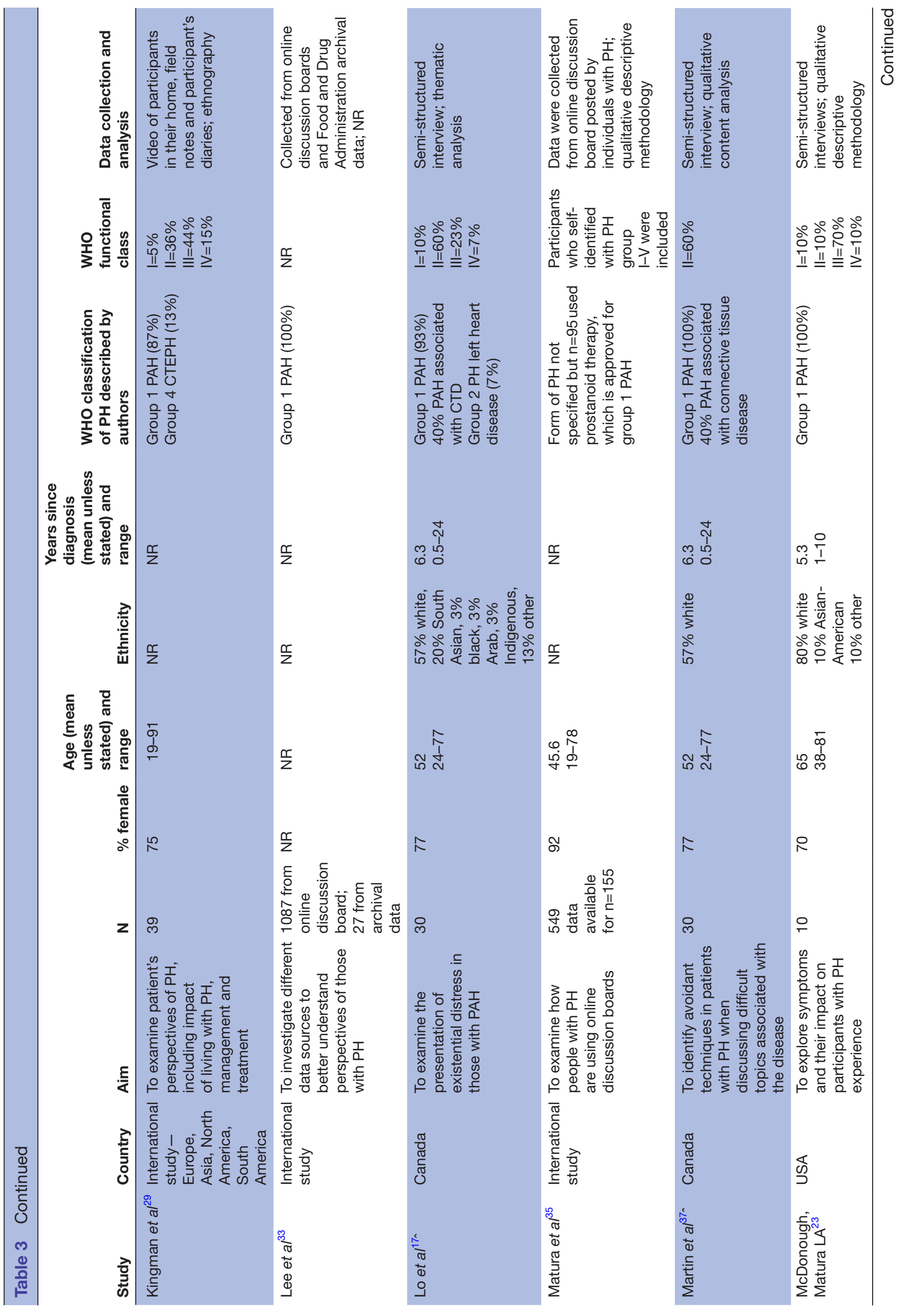




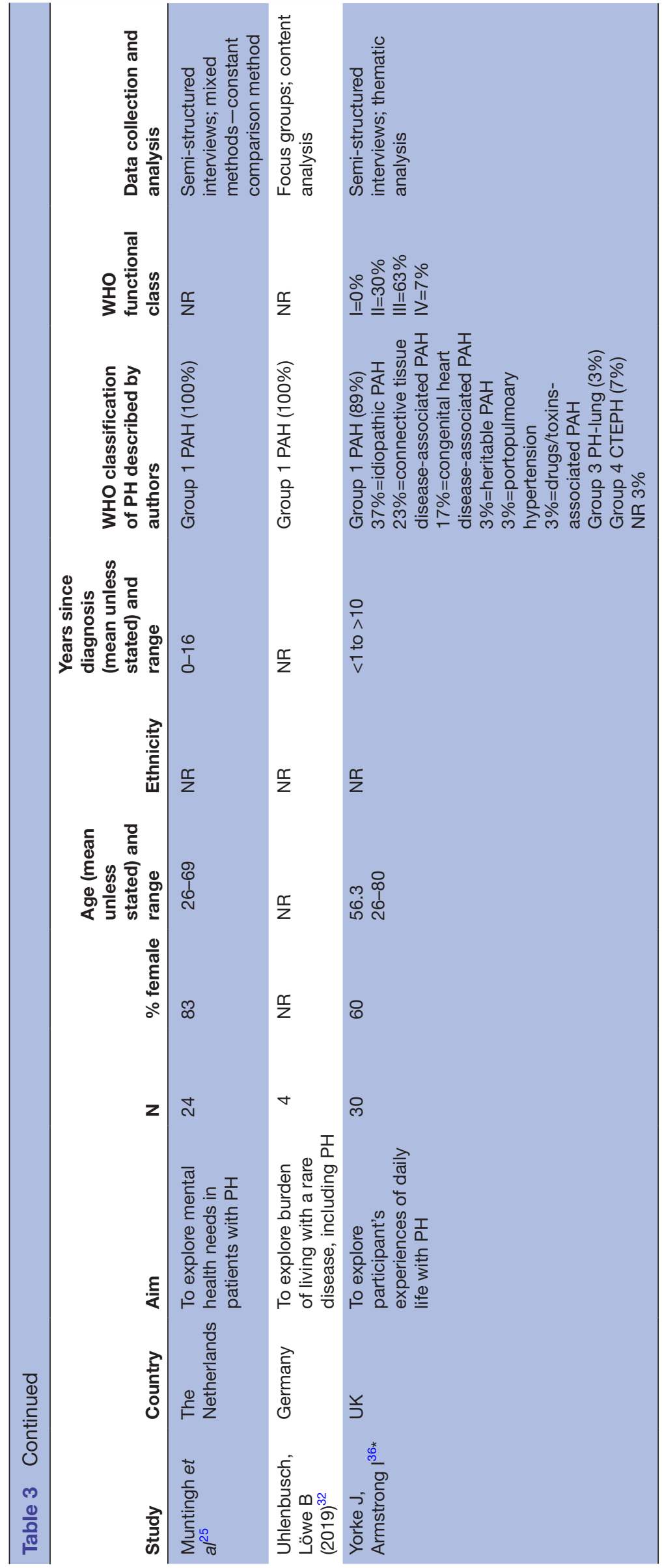

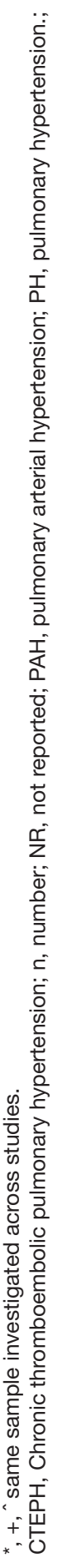


Table 4 Quality assessment using critical appraisal skills programme ${ }^{18}$

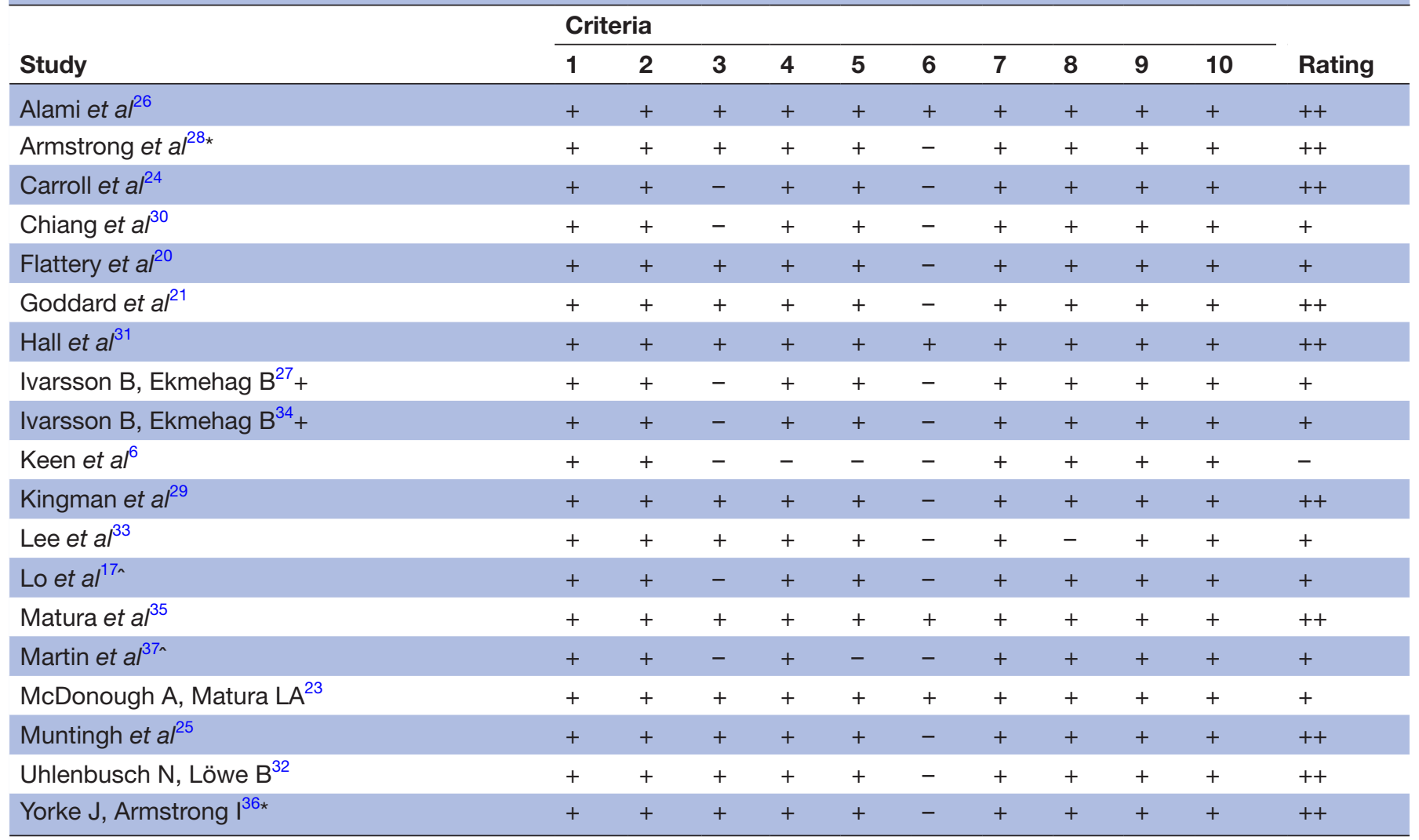

${ }^{*},+$, s same sample investigated across studies.

Was the research aim(s) (1) clearly stated and $(2,3)$ addressed using a qualitative approach. Evaluation of the: (4) recruitment strategy, (5) data collection method, (6) issues concerning reflexivity, (7) ethical implications, (8) data analysis, (9) clarity of findings and (10) overall value of the research.

ultimately, survival: "[if medication was stopped] Well, all of us would die. It's as simple as that" [25, 27, 29, 31-33, 38, p. 458]. Many reported an almost immediate reduction in symptoms attributed to treatment, ${ }^{27} 34$ with a 'strong emotional attachment' to medication being noted [25, 33, p. 5].

Side effects of treatments were common, which seemed to mostly manifest physically. ${ }^{20} 2332$ There was uncertainty surrounding side effects as participants reflected that it was not always clear whether their symptoms were associated with the disease itself or psychosocial burden of $\mathrm{PH}^{33}{ }^{35}$ Side effects posed as a barrier to adherence, as while some viewed the negatives of treatment as a tradeoff: "it's added years to my life...but it's bittersweet" [21, p. 102], others stopped despite the risk. ${ }^{36}$

Other barriers were discussed such as, accessibility and cost of treatment, emotional distress and problems with self-administration. ${ }^{232431-3436}$ Lack of perceived need also affected uptake as while many experienced emotional difficulties, some felt they did not need psychological support, ${ }^{34}$ perceiving: "the disease itself is the problem" [29, p. 4]. However, some expressed the need for help with managing anxiety and low mood. ${ }^{25}$

Participants described a number of worries associated with their treatment, such as, whether it was effective ${ }^{20}$ and if so for how long, ${ }^{36}$ potential risks, ${ }^{31}$ what other options are available ${ }^{293136}$ and the wait to receive treatment. ${ }^{17}$ Visible treatments could be a source of "social stigma' [27, 38, p. 456], leaving participants feeling 'selfconscious' $[33$, p. 4$]$.

\section{Prognosis}

Participants were saddened, ${ }^{30}$ "terrified" [35, p. 162] and anxious over the prospect of their death. ${ }^{1725}$ Individuals described many uncertainties associated with their prognosis including, how their disease would progress, ${ }^{23} 35$ what their future would hold, ${ }^{34}$ the impact of their death on loved ones ${ }^{172125}$ and how long they had remaining: "I am clueless as to how long my heart will hold out" [29, p. 3]. One women wondered if her death would make it "easier" due to the impact of $\mathrm{PH}$ on her family $[17, \mathrm{p} .4]$. The pervasive fear over when or how their symptoms would worsen 'plagued' participants [24, p. 129], resulting in emotional and psychological difficulties. ${ }^{23} 34$

\section{Healthcare professionals}

Developing a therapeutic relationship with a PH "expert" was important [33, p. 5]. Professionals were described as a source of support, ${ }^{34}$ advice, ${ }^{6}$ knowledge ${ }^{31}$ reassurance, ${ }^{28}$ motivation and 'hope' [29, 31, p. 4]. That said, participants 
reported some difficulties accessing or discussing their worries with professionals, ${ }^{26}{ }^{27}$ as well as previous encounters in which professionals lacked competency, ${ }^{32}$ empathy or sensitivity: one participant, for example, reported being told "It's $[P H]$ worse than cancer, we can't treat it" [28, p. 3].

Participants expressed their frustration over healthcare professionals' poor understanding of PH. ${ }^{28} 3132$ Individuals spoke of pleading or taking it on themselves to explain the disease to staff. ${ }^{21} 27$

\section{Impact}

A range of symptoms were experienced by participants including, dyspnoea, pain, dizziness, fatigue, palpitations and cognitive difficulties. ${ }^{20} 2123263235$ Breathing problems, however, were described as the "main symptom" [27, p. E16], which was associated with feelings of breathlessness, 'suffocating', 'choking' and 'pain'-this was closely interlinked with anxiety [24, 27, p. E16]. Breathing could become a 'conscious act' [27, p. E16], as participants provided precise details over which activities would cause them shortness of breath [27, p. E17]. That said, some symptoms were 'unpredictable' and likened to being on a 'rollercoaster' [30, 38, p. 456].

Decline in physical ability, mobility and energy levels were prevalent, ${ }^{25} 30$ which could be caused by any form of activity. ${ }^{23} 2631$ Participated expressed 'fear' of engaging in activities [33, p. 4] due to the onset of symptoms, pain ${ }^{23}$ or it requiring too much energy. ${ }^{34}$ There seemed to be a discrepancy between participant's ideal and actual self, in terms of ability, ${ }^{26}$ which manifested in feelings of 'anger' [24, p. 129], "failing" [22, p. 4], 'disappointment' [32, p. 38] and shame. ${ }^{34}$

Individuals had to reduce or cease many activities, ${ }^{17} 2637$ leading them to relate their situation to a "shackle" [33, p. 4]. Reflected in this, was the feeling of restriction, the nature of which had a considerable impact on profession, family and social roles. ${ }^{17} 212526303233$ This appeared to be, somewhat, moderated by age, gender and stage of the disease. ${ }^{1725}$ For example, younger participants had to limit themselves to activities that matched their 'activity tolerance'opposed to interests [33, p. 4]. Participants reported sexual difficulties largely due to fatigue and shortness of breath, which negatively affected their relationship. ${ }^{17} 2634$ Financial problems associated with the cost of care and loss of earnings. ${ }^{25} 3032$ Practical and emotional problems caused by travelling. ${ }^{31}{ }^{34}$ Male and female participants discussed difficulties associated with having or caring for their children. ${ }^{1721252734}$

There was a general sense that the disease could be invisible and "hidden" from others [38, p. 456]. Family, friends, the public, local authorities, insurance companies and even healthcare professionals were all described, at times, as failing to understand the disease and participant's physical limitations. ${ }^{17} 202627323436$ Participants found themselves having to 'battle' for their illness to be recognised [38, p. 458], and justify their difficulties. ${ }^{27} 34$
Life with PH could have a negative effect on participant's mental health, with anxiety, low mood, isolation $^{2325293235}$ and suicidal ideation being discussed. ${ }^{3037}$

\section{Coping}

Participants required a period of time to adjust to life with $\mathrm{PH}^{20} 233036$ Individuals coped differently, for example, an international study observed two approaches: 'disease dominated' whereby participants harboured a 'passive attitude towards $P H$ ', were dependent on others, and likely to experience depression; whereas 'solution seekers' developed strategies to manage, were less dependent and maintained a social life [33, p. 4].

A common approach to coping was preparation, ${ }^{21}$ 'extensive planning' and developing 'daily routines' [30, 33 , p. 5]. Individuals discussed weighing up how activities would impact them, rather than "act on impulse" [24, p. 127]. Participants reported feeling like they had to 'hold back or take it [daily activities] slow' [21, 24, p. 127]. Personal limits were learnt through 'testing' their own ability [30, p. 39].

Many acknowledged the importance of developing a helpful or positive "mindset" [26, 29, p. 4], for example, focusing on activities that were still within their ability ${ }^{23}$ : "I tell myself that I have to look at what I can still do..." [30, p. 39]. Self-talk, ${ }^{31}$ focusing on having overcome previous adversity, ${ }^{37}$ faith $^{20}$ and self- humour were also used to cope. $^{2021}$

Altering expectations of ability, recovery and future ${ }^{25-27} 36$ allowed some to develop a new sense of purpose $^{31}$ or "redefine" their lives [24, p. 128, 27, 35]. Accepting their limits gave participants the perception that they were not letting their disease "dominate" [25, 26, 33, p. 4] and provided a sense of $\operatorname{control}^{23}$ : “...it's just my life, it's just what I do" [21, p. 102]. Keeping active was described as helping to shift their focus away from their symptoms, ${ }^{35}$ control disease progression and have psychological benefits. ${ }^{6}$

Family, friends and employers were described as offering practical and emotional support. ${ }^{25} 29303435$ However, participants appeared conflicted, describing their own position as "enforced dependency" [17, 33, p. 3]. Social support could also be a barrier or counterproductive to coping, as how others dealt with the disease was not always helpful. ${ }^{32} 34$

Participants spoke about concealing, avoiding, diminishing and making excuses for their difficulties. ${ }^{1721} 29303637$ This helped reduce some of the emotional impact of $\mathrm{PH}$, as well as feeling less of a burden or protecting others. ${ }^{313437}$ However, this could lead to social withdrawal and isolation, further straining relationships and causing psychological difficulties. 252930

Peer supports groups and organisations were common sources of reassurance, support and advice. ${ }^{32}{ }^{34}$ Individuals sought validation and normalisation of their symptoms from people with shared experience ${ }^{35}$ and also looked to help others. ${ }^{24}$ 


\section{Analytical themes}

Four key analytical themes emerged:

\section{Managing uncertainty}

Participants acknowledged many uncertainties caused by internal, such as bodily sensations, or external events linked to $\mathrm{PH}$, including the reaction of others ${ }^{26}$ or what the future may hold. ${ }^{17}$ Uncertainty was often associated with a perception of risk or threat, which precipitated and perpetuated psychological, emotional and physiological distress. Many of the approaches that participants employed to manage their difficulties related to uncertainty seemed to only provide brief relief, until the next unknown situation occurred, or their strategy fed back into their level of distress, for example:

Participants sought information and reassurance from a range of sources, ${ }^{20}$ in the hope of gaining knowledge, understanding and some sense of certainty. ${ }^{28}$ Unfortunately, given the complexity and lack of understanding of $\mathrm{PH}$, this could result in even greater uncertainty. ${ }^{28}$

Individuals seemed to engage in worry as a helpful means to problem solve, plan and minimise negative outcomes. However, planning could be impractical due to the unpredictable nature of $\mathrm{PH}^{36}$ or it removed spontaneity in their life' [24, p. 127]. Worrying was also closely linked with hypervigilance to the impact of everyday activities $^{23}$ and somatic changes as an 'indicator' to alter behaviour [22, 27, p. E17]. This resulted in anticipatory anxiety and panic. ${ }^{23}$

Some described avoiding ${ }^{25} 37$ or concealing their disease, however, this often prolonged distress and resulted in emotional difficulties, such as anxiety, guilt and loneliness. ${ }^{17}$

\section{Physical nature of PH}

$\mathrm{PH}$ was described as a physically limiting disease, ${ }^{32}$ as was there a tendency for individuals to report somatic experiences. ${ }^{21} 2326$ Furthermore, despite experiencing emotional difficulties, participants often resisted the idea or need for psychological support. ${ }^{25} 3237$ A notion further reflected in the relief on hearing the disease was not psychosomatic in nature. ${ }^{28}$

Conversely, participant's social environment did not always recognise the physical manifestations of the disease-participants assumed because "you can't see anything" and most of the time they "look fine" as there was a lack of visible signs $[26,38$, p. 455]. Discordance between the meaning and impact participants and others attached to the disease seemed most salient on occasions when physical adaptations were required due to fatigue or breathlessness-symptoms of which could be invisible to others. ${ }^{25}{ }^{34}$ It seemed the support participant's received was, at times, influenced by other's representation of the disease. ${ }^{21}$ Likewise, participant's own perceptions of their circumstance may have affected their experiences of coping, which could help, in part, to explain resistance to psychological support.

\section{Living with the rarity of $\mathrm{PH}$}

The rarity of PH was highlighted in discussions, ${ }^{25}{ }^{26}$ no more so than when individuals expressed their frustration at the lack of PH awareness in society and healthcare. $^{27} 32$ Lack of understanding and misconceptions over $\mathrm{PH}$ resulted in participants feeling stigmatised and discriminated against. ${ }^{21} 2532$ Participants found themselves having to justify and legitimise their sick role, despite having an incurable disease ${ }^{32} 36$ or withdrawing to avoid difficulties. ${ }^{17}$ Individuals felt the need to become experts in $\mathrm{PH}$, which made it all the more frustrating when others assumed that they knew better or when participant's voices were unheard in care. ${ }^{21}{ }^{27}$ Living with a rare condition left individuals feeling lonely and isolated: "forced to carry a burden no one wants, or understands fully" [33, p. 4]. Participants found understanding from experts in $\mathrm{PH}$ and PH communities. ${ }^{20}$

\section{Transitional nature of PH}

Participants progressed through different transitions living with $\mathrm{PH} .{ }^{25}$ At first, experiencing a decline in general functioning, which appeared to improve following the diagnosis and administration of treatment. ${ }^{28}$ Participants next faced the process of adapting to life with $\mathrm{PH}$ and treatment, ${ }^{20}{ }^{31}$ the goal of which was to stabilise the disease ${ }^{6}$ maintain a good QoL and survive. ${ }^{25}$ Participants had to find a balance between feeling underactive, in which they perceived their identity as changing ${ }^{17}$ and themselves "failing" [22, p. 4], and overactive, whereby participants attempted to resume normal life despite the risk and increase in $\mathrm{PH}$ symptoms, or dissonance feeling torn between societal norms and their own ability. ${ }^{23}$ This balance was often achieved through 'trial and error' [30, p. 39] and becoming more aware of physical, psychological, family and society cues.

\section{DISCUSSION}

This review presents the first systematic synthesis of qualitative data exploring adults' experiences of living with PH. Four analytical themes emerged reflecting: how individuals navigate uncertainty associated with $\mathrm{PH}$; the physical and somatic nature of $\mathrm{PH}$; implications of living with a rare disease and the transitional nature of adapting to life with $\mathrm{PH}$.

Feelings of uncertainty are commonly experienced by individuals with a rare medical condition. ${ }^{38}$ For participants in the current review, uncertain events were often perceived as threatening resulting in distress. Intolerance to uncertainty is one of the main theories aimed at understanding generalised anxiety disorder (GAD).$^{39}$ In GAD, individuals find the feeling of uncertainty difficult. This distress is often managed by engaging in worry as a method to prepare for possible eventualities. The associated anxiety however influences individuals to appraise and overestimate events as negative and threatening. As observed here, this can generate greater uncertainty and anxiety. ${ }^{39} 40$ A study investigating GAD in PH found 93\% 
reported some symptoms. ${ }^{41}$ Symptoms of GAD in PH has been found to be associated with depression, ${ }^{41}$ which may impact patient's ability to adapt to the challenges of $\mathrm{PH}^{4}{ }^{4}$ Although anxiety and depression in $\mathrm{PH}$ is common, just over one-third of patients receive treatment. ${ }^{43}$ Strategies aimed at helping individuals to better manage distress associated with uncertainty are likely to be useful. A range of psychological treatments have been shown to be effective for GAD ${ }^{44}$ however, there is paucity of evidence regarding psychological treatments in $\mathrm{PH} .{ }^{45}$

Participants focused primarily on the physical difficulties of PH. While this may indeed be how the disease presents, individuals described becoming more aware of somatic feedback to help gauge their own body. Individuals investigated elsewhere who experienced chest pain have also reported hypervigilance to cardiopulmonary sensations. The degree of vigilance was positively related to chest pain, the association of which was mediated by fear of bodily sensations. ${ }^{46} \mathrm{~A}$ similar relationship can be observed in Clark's model of panic, whereby perceptions of threat and anxiety over somatic symptoms increase the likelihood of experiencing, and also misinterpreting, a bodily sensation as negative. ${ }^{47}$ Individuals with PH should be supported to better understand and differentiate the shared overlap between cardiovascular symptoms and anxiety. ${ }^{48}$ Interventions, such as mindfulness, that help individuals disengage their attention from sensations may also be beneficial. ${ }^{49}$

Disparity in illness perceptions between participants and others was a common source of distress. This has also been reported in other diagnoses that are associated with poor understanding and uncertainty. ${ }^{50}$ Such incongruences have been suggested to influence how individuals present to services with their symptoms and adherence to treatment. ${ }^{51}$ Healthcare professionals may benefit from additional training on $\mathrm{PH}$, as well as developing skills to help explore individual's understanding of the disease, and perceived psychosocial impact. ${ }^{52}$ While greater consideration of individual's social support in $\mathrm{PH}$ care will likely minimise the impact and degree of conflicting perceptions, helping patients to develop skills to manage conversations when other people are confused about PH is also important. ${ }^{53}$

PH care should reflect the transitional nature involved in adapting to life with $\mathrm{PH}$. This may help to minimise or prevent worsening of psychosocial symptoms following their PH diagnosis. ${ }^{54}$ Initially, individuals are likely to value from additional support in understanding $\mathrm{PH}$, managing the emotional impact of the diagnosis and integrating the disease into their identities exploring existential worries. For example, caregivers should help individuals to explore their difficulties and construct new meaning. ${ }^{55}$ Experiences of fatigue appeared a prominent theme thereafter as individuals aimed to find a balance between their energy and engaging in activities. Fatigue is the second most common symptom patients with $\mathrm{PH}$ present with. ${ }^{52}$ Supporting individuals to manage fatigue through education, pacing and prioritising valued actions is likely to helpful—this may also reduce mood disorders. ${ }^{56}$

\section{Limitations}

Most studies did not discuss reflexivity. This involves the researcher attending to the wider content of knowledge acquisition, discussing the potential role of relationships between participants and themselves in their investigation. ${ }^{57}$ This is an important stage in some qualitative research approaches and also contributes to rigour and trustworthiness. $^{58}$

Due to lack of reporting, the analysis was unable to distinguish between experiences based on PH-related factors, which has been shown to be associated with psychological distress. ${ }^{59}$ Grouping individuals based solely on their diagnosis of PH may have resulted in idiosyncratic findings being missed. Moreover, experiences relating to palliative care, pregnancy, surgery and psychological interventions were largely unrepresented despite being commonly encountered in practice.

Finally, the review protocol has been registered on Open Science Framework registries; while it was not registered prior to data extraction, authors confirm that the protocol had not been altered since it was initially devised and prior to data extraction.

\section{CONCLUSION}

This review uniquely thematically synthesises qualitative data from over 1900 individuals with $\mathrm{PH}$ across four continents, with the majority of participants recruited in two international studies. ${ }^{33} 35$ The review finds numerous voices are missing, which needs addressing, including those from palliative care, non-white background and individuals who have experienced pregnancy in $\mathrm{PH}$. The results have implications for clinical practice highlighting the potential role of education and psychological therapies to support those with the disease.

Acknowledgements The authors would like to thank Christopher Gaskell (CK), a Trainee Clinical Psychologist from the University of Sheffield, for his help in rating the quality of included studies.

Contributors GHR was responsible for the conception of the review, data collection and analysis, and writing the report for publication. He approved the final version for publication. NB made substantial contributions to research design and provided feedback on data analysis and final report. He approved the final version for publication. IA made contributions to data analysis and provided feedback on the final report. He approved the final version for publication. RC made contributions to data collection, analysis and provided feedback on the final report. He approved the final version for publication. DGK made contributions to data analysis and provided feedback on the final report. He approved the final version for publication. IS made contributions to data collection, analysis and provided feedback on the final report. He approved the final version for publication. ART was responsible for the conception of the review, made substantial contributions to the research design and provided feedback on data analysis and final report. He approved the final version for publication.

Funding The authors have not declared a specific grant for this research from any funding agency in the public, commercial or not-for-profit sectors.

Competing interests GHR, NB, ART, RC and IA have no conflict of interests to report. DGK has received honoraria from Actelion, Bayer, GSK and MSD for participation as a speaker and consultancy work and his unit has received research and unrestricted educational grants from Actelion and GSK. IS's department 
receives an unrestricted educational grant from GSK for an annual clinical education meeting.

Patient consent for publication Not required.

Provenance and peer review Not commissioned; externally peer reviewed.

Data availability statement № data are available. The current article was a systematic synthesis of data that had already been published.

Supplemental material This content has been supplied by the author(s). It has not been vetted by BMJ Publishing Group Limited (BMJ) and may not have been peer-reviewed. Any opinions or recommendations discussed are solely those of the author(s) and are not endorsed by BMJ. BMJ disclaims all liability and responsibility arising from any reliance placed on the content. Where the content includes any translated material, BMJ does not warrant the accuracy and reliability of the translations (including but not limited to local regulations, clinical guidelines, terminology, drug names and drug dosages), and is not responsible for any error and/or omissions arising from translation and adaptation or otherwise.

Open access This is an open access article distributed in accordance with the Creative Commons Attribution Non Commercial (CC BY-NC 4.0) license, which permits others to distribute, remix, adapt, build upon this work non-commercially, and license their derivative works on different terms, provided the original work is properly cited, appropriate credit is given, any changes made indicated, and the use is non-commercial. See: http://creativecommons.org/licenses/by-nc/4.0/.

\section{ORCID iDs}

Gregg Harry Rawlings http://orcid.org/0000-0003-4962-3551

Nigel Beail http://orcid.org/0000-0002-7916-9313

lain Armstrong http://orcid.org/0000-0001-5898-3087

Robin Condliffe http://orcid.org/0000-0002-3492-4143

David G Kiely http://orcid.org/0000-0003-0184-6502

lan Sabroe http://orcid.org/000-0001-9750-8975

Andrew R Thompson http://orcid.org/0000-0001-6788-7222

\section{REFERENCES}

1 Hoeper MM, Bogaard HJ, Condliffe R, et al. Definitions and diagnosis of pulmonary hypertension. J Am Coll Cardiol 2013;62:D42-50.

2 McGoon M, Gutterman D, Steen V, et al. Screening, early detection, and diagnosis of pulmonary arterial hypertension. Chest 2004;126:14S-34.

3 Hoeper MM, Ghofrani H-A, Grünig E, et al. Pulmonary hypertension. Dtsch Arztebl Int 2017;114:73-84.

4 Kiely DG, Elliot CA, Sabroe I, et al. Pulmonary hypertension: diagnosis and management. BMJ 2013;346:f2028.

5 Galiè N, Humbert M, Vachiery J-L, et al. ESC/ERS guidelines for the diagnosis and treatment of pulmonary hypertension. European Heart Journal 2016;37:67-119.

6 Keen C, Fowler-Davis S, McLean S, et al. Physiotherapy practice in pulmonary hypertension: physiotherapist and patient perspectives. Pulm Circ 2018;8:2045894018783738.

7 McGoon MD, Ferrari P, Armstrong I, et al. The importance of patient perspectives in pulmonary hypertension. Eur Respir $J$ 2019;53:1801919.

8 Halimi L, Marin G, Molinari N, et al. Impact of psychological factors on the health-related quality of life of patients treated for pulmonary arterial hypertension. J Psychosom Res 2018;105:45-51.

9 Cole E, Armstrong I, Cutts K. Links between psychological factors and health- related quality of life in pulmonary hypertension. The European Respiratory Journal 2016;48.

10 Delcroix M, Howard L. Pulmonary arterial hypertension: the burden of disease and impact on quality of life. Eur Respir Rev 2015;24:621-9.

11 Graarup J, Ferrari P, Howard LS. Patient engagement and selfmanagement in pulmonary arterial hypertension. Eur Respir Rev 2016;25:399-407.

12 McKenna SP, Doughty N, Meads DM, et al. The Cambridge pulmonary hypertension outcome review (camphor): a measure of health-related quality of life and quality of life for patients with pulmonary hypertension. Qual Life Res 2006;15:103-15.

13 Bonner N, Abetz L, Meunier J, et al. Development and validation of the living with pulmonary hypertension questionnaire in pulmonary arterial hypertension patients. Health Qual Life Outcomes 2013;11:161.

14 Yorke J, Corris P, Gaine S, et al. emPHasis-10: development of a health-related quality of life measure in pulmonary hypertension. Eur Respir J 2014;43:1106-13.
15 Harper D, Thompson AR. Qualitative research methods in mental health and psychotherapy: a guide for students and practitioners. Oxford: Wiley-Blackwell, 2012.

16 Tong A, Flemming K, Mclnnes E, et al. Enhancing transparency in reporting the synthesis of qualitative research: ENTREQ. BMC Med Res Methodol 2012;12:181.

17 Lo C, Sarker T, Canning O, et al. Clinical presentation of existential distress in pulmonary arterial hypertension. Canadian Journal of Respiratory, Critical Care, and Sleep Medicine 2019;3:56-62.

18 Critical appraisal skills programme. CASP qualitative checklist, 2018. Available: https://casp-uk.net/wp-content/uploads/2018/03/CASPQualitative-Checklist-2018 fillable form.pdf;

19 Thomas J, Harden A. Methods for the thematic synthesis of qualitative research in systematic reviews. BMC Med Res Methodol 2008;8:45.

20 Flattery MP, Pinson JM, Savage L, et al. Living with pulmonary artery hypertension: patients' experiences. Heart Lung 2005;34:99-107.

21 Goddard JC, Armstrong IJ, Kiely DG, et al. Combining creative writing and narrative analysis to deliver new insights into the impact of pulmonary hypertension. BMJ Open Respir Res 2017:4:e000184.

22 Hoeper MM, Simon R Gibbs J, Gibbs SR. The changing landscape of pulmonary arterial hypertension and implications for patient care. Eur Respir Rev 2014;23:450-7.

23 McDonough A, Matura LA, Carroll DL. Symptom experience of pulmonary arterial hypertension patients. Clin Nurs Res 2011;20:120-34

24 Carroll R, Antigua J, Taichman D, et al. Motivations of patients with pulmonary arterial hypertension to participate in randomized clinical trials. Clin Trials 2012;9:348-57.

25 Muntingh ADT, Gerritsen S, Batelaan NM, et al. Pathways to experiencing mental problems and need for mental support in patients with pulmonary arterial hypertension. Pulm Circ 2017;7:609-16.

26 Alami S, Cottin V, Mouthon L, et al. Patients', relatives', and practitioners' views of pulmonary arterial hypertension: a qualitative study. Presse Med 2016;45:e11-27.

27 Ivarsson B, Ekmehag B, Sjöberg T. Information experiences and needs in patients with pulmonary arterial hypertension or chronic thromboembolic pulmonary hypertension. Nurs Res Pract 2014;2014:1-8

28 Armstrong I, Rochnia N, Harries C, et al. The trajectory to diagnosis with pulmonary arterial hypertension: a qualitative study. BMJ Open 2012;2:e000806.

29 Kingman M, Hinzmann B, Sweet O, et al. Living with pulmonary hypertension: unique insights from an international ethnographic study. BMJ Open 2014;4:e004735.

30 Chiang Y-C, Hu L-Y, Couper J, et al. Exploring the experiences and psychosocial stresses of Taiwanese patients with pulmonary hypertension: a qualitative interview study. Pulm Circ 2018;8:2045894018787479.

31 Hall H, Côté J, McBean A, et al. The experiences of patients with pulmonary arterial hypertension receiving continuous intravenous infusion of epoprostenol (Flolan) and their support persons. Heart Lung 2012;41:35-43.

32 Uhlenbusch N, Löwe B, Depping MK. Perceived burden in dealing with different rare diseases: a qualitative focus group study. BMJ Open 2019;9:e033353.

33 Lee C, St Clair C, Merenda CC, et al. Assessment of public and patient online comments in social media and food and drug administration archival data. A pilot qualitative analysis Research in social \& administrative pharmacy. Research in Social and Administravei Pharmacy 2019:10:S1551.

34 Ivarsson B, Ekmehag B, Sjöberg T. Support experienced by patients living with pulmonary arterial hypertension and chronic thromboembolic pulmonary hypertension. Heart Lung Circ 2016;25:35-40

35 Matura LA, McDonough A, Aglietti LM, et al. A virtual community: concerns of patients with pulmonary hypertension. Clin Nurs Res 2013;22:155-71.

36 Yorke J, Armstrong I, Bundock S. Impact of living with pulmonary hypertension: a qualitative exploration. Nurs Health Sci 2014;16:454-60.

37 Martin V, Sarker T, Slusarek E, et al. Conversational avoidance during existential interviews with patients with progressive illness. Psychol Health Med 2020;25:1073-82.

38 von der Lippe C, Diesen PS, Feragen KB. Living with a rare disorder: a systematic review of the qualitative literature. Mol Genet Genomic Med 2017;5:758-73.

39 Dugas MJ, Robichaud M. Practical clinical guidebooks. Cognitivebehavioral treatment for generalized anxiety disorder: From science to practice. New York: Routledge, 2007. 
40 Bottesi G, Ghisi M, Carraro E, et al. Revising the intolerance of uncertainty model of generalized anxiety disorder: evidence from UK and Italian undergraduate samples. Front Psychol 2016;7:7.

41 Harzheim D, Klose H, Pinado FP, et al. Anxiety and depression disorders in patients with pulmonary arterial hypertension and chronic thromboembolic pulmonary hypertension. Respir Res 2013;14:104

42 Wryobeck JM, Lippo G, McLaughlin V, et al. Psychosocial aspects of pulmonary hypertension: a review. Psychosomatics 2007;48:467-75.

43 Somaini G, Hasler E, Muller-Mottet S, et al. Anxiety and depression are highly prevalent in pulmonary hypertension and might improve with target therapy. European Respiratory Journal 2015;46:PA2112.

44 Hunot V, Churchill R, Teixeira V, Silva de Lima M, et al. Psychological therapies for generalised anxiety disorder. Cochrane Database Systematic Reviews 2007;7:CD001848.

45 Bussotti M, Sommaruga M. Anxiety and depression in patients with pulmonary hypertension: impact and management challenges. Vasc Health Risk Manag 2018;14:349-60.

46 White KS, Craft JM, Gervino EV. Anxiety and hypervigilance to cardiopulmonary sensations in non-cardiac chest pain patients with and without psychiatric disorders. Behav Res Ther 2010;48:394-401.

47 Clark DM. A cognitive approach to panic. Behav Res Ther 1986;24:461-70.

48 Fleet RP, Beitman BD. Cardiovascular death from panic disorder and panic-like anxiety: a critical review of the literature. $J$ Psychosom Res 1998;44:71-80.

49 Tulloh RMR, Garratt V, Tagney J, et al. A pilot randomised controlled trial investigating a mindfulness-based stress reduction (MBSR) intervention in individuals with pulmonary arterial hypertension (PAH): the pathways study. Pilot Feasibility Stud 2018;4:78.

50 Whitehead K, Kandler R, Reuber M. Patients' and neurologists perception of epilepsy and psychogenic nonepileptic seizures. Epilepsia 2013;54:708-17.

51 Monzoni CM, Duncan R, Grünewald R, et al. Are there interactiona reasons why doctors may find it hard to tell patients that their physical symptoms may have emotional causes? A conversation analytic study in neurology outpatients. Patient Educ Couns 2011;85:e189-200

52 Fenstad ER, Shanafelt TD, Sloan JA, et al. Physician attitudes toward palliative care for patients with pulmonary arterial hypertension: results of a cross-sectional survey. Pulm Circ 2014;4:504-10.

53 Clarke A, Thompson AR, Jenkinson E, et al. CBT for appearance anxiety : psychosocial interventions for anxiety due to visible difference. Chichester: Wiley Blackwell, 2014.

54 Halimi L, Molinari N, Marin G, et al. Quality of life in worsening and non-worsening PAH patient's in a 1 year follow-up: What's going on? European Respiratory Journal 2015;46:PA705.

55 Egnew TR. A narrative approach to healing chronic illness. Ann Fam Med 2018;16:160-5.

56 Connolly D, O'Toole L, Redmond P, et al. Managing fatigue in patients with chronic conditions in primary care. Fam Pract 2013;30:123-4.

57 Dodgson JE. Reflexivity in qualitative research. J Hum Lact 2019;35:220-2

58 Larkin M, Thompson A. Interpretative Phenomenological Analysis in Mental Health and Psychotherapy Research. In: Harper D, Thompson AR, eds. Qualitative research methods in mental health and psychotherapy. Wiley-Blackwell, 2012: 101-16.

59 Yorke J, Deaton C, Campbell M, et al. Symptom severity and its effect on health-related quality of life over time in patients with pulmonary hypertension: a multisite longitudinal cohort study. BM Open Respir Res 2018;5:e000263.

60 Yorke J, Armstrong I, Deaton C, et al. Patient rated who functional class and psychological distress are strongly associated with dyspnoea in pulmonary hypertension. European Respiratory Journal 2015;46:PA331.

61 Methley AM, Campbell S, Chew-Graham C, et al. PICO, PICOS and spider: a comparison study of specificity and sensitivity in three search tools for qualitative systematic reviews. BMC Health Serv Res 2014; 14:579. 